\title{
DESIGN OF A COMPOSITE LEAF SPRING FOR RAILWAY VEHICLES
}

\author{
Frantisek Sedlacek, Petr Bernardin, Vaclava Lasova
}
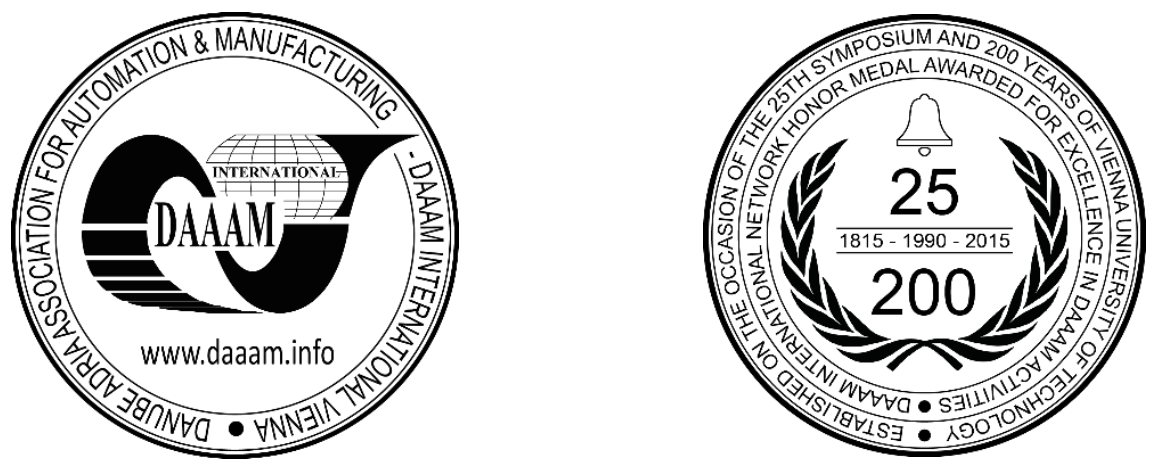

This Publication has to be referred as: Sedlacek, F[rantisek]; Bernardin, P[etr] \& Lasova, V[aclava] (2016). Design of a Composite Leaf Spring for Railway Vehicles, Proceedings of the 27th DAAAM International Symposium, pp.04930500, B. Katalinic (Ed.), Published by DAAAM International, ISBN 978-3-902734-08-2, ISSN 1726-9679, Vienna, Austria

DOI: $10.2507 / 27$ th.daaam.proceedings.074

\begin{abstract}
The paper deals with the design/optimization of a leaf spring for railway vehicles using composite materials. The optimization was carried out based on the main mechanical parameters of the current design solution for steel leaf springs. A numerical simulation was created to obtain the data, then the simulation was verified using an experimental test. Glass fibre reinforcement with epoxy resin was chosen as the material for the composite leaf spring. The main shape of the composite leaf spring was created using geometrical optimization. An advanced finite element model which modelled individual plies of the laminate was created to check the strength of the composite spring. A maximum stress strength criterion and transverse shear interlaminar criterion were used to evaluate the failure index.
\end{abstract}

Keywords: composite materials; leaf spring; numerical simulation; geometric optimization; maximum stress failure criterion

\section{Introduction}

The use of composite materials as structural material is no longer a privilege of elite design in the aerospace industry or motorsport, but it is increasingly applied to private cars and railway vehicles. One of the best applications is for vehicle springs. Using composite materials in the construction of springs not only ensures a great reduction in weight, but also has a whole range of other advantages: the possibility of reducing vibration, noise and ride harshness due to high damping factors; the absence of corrosion (lower maintenance cost); lower tooling cost (lower manufacturing cost) [1].

The design of composite springs has already been dealt with in several works: Beardmore [2] or Morris [3] were dealt with a design composite leaf spring for private cars; Daugherty [4] was dealt with using a composite leaf spring for trucks; Krall [5] was dealt with investigation of the dynamic behaviour of the composite leaf springs and Mahdi [6] and Talib [7] were dealt with very similar solution with elliptic springs for vehicle suspension.

However, this article deals with the optimization of leaf springs for heavy vehicles; specifically, for rail tram vehicles. The basic shape of the composite leaf spring is sought with the help of a geometrical optimization. 


\section{The current solution}

The current solution is a conventional steel leaf spring, which is composed from six plates. The individual plates of the spring are connected using a central housing with a connecting pin. The mounting of the leaf spring is ensured by two eyes which are a part of the lower leaf spring. The current design solution for a steel leaf spring is shown in Fig. 1.

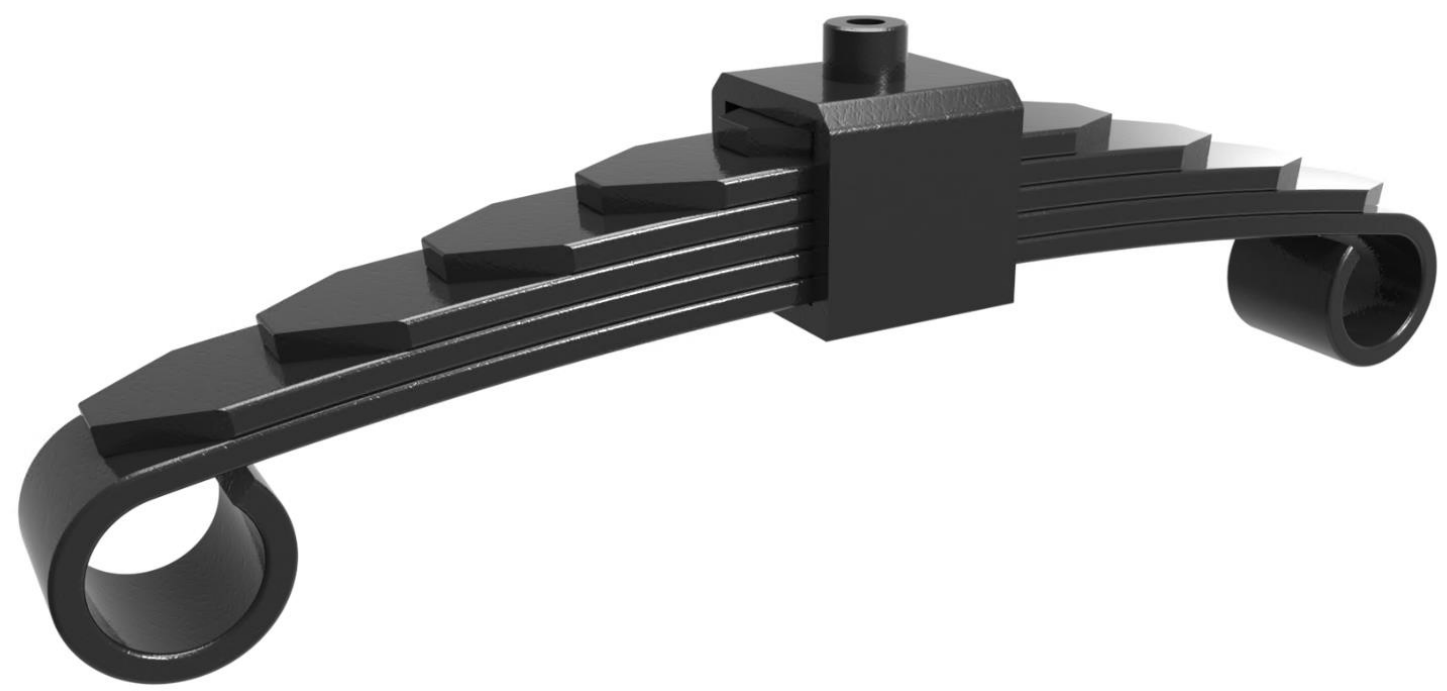

Fig. 1. Current solution - steel leaf spring

\section{Determination of the basic parameters}

A numerical simulation of the current design solution of the steel leaf spring was carried out to obtain the basic parameters of the spring (in particular, the stiffness of the spring). The five steel leaf spring was experimentally tested to validate the numerical simulation.

\subsection{Numerical simulation of the current solution (steel leaf spring)}

In the first phase, a finite element model of the assembly of the leaf spring was created. A 3D finite element mesh (combination of the elements; CQUAD8 and CTRIA4) was applied to the model of the spring (see Fig. 2.). Steel 1.7106 (56SiCr7 according to EN10089) was used. This material is one of the most common types used for steel leaf springs. Its mechanical properties are given in Table 1. The physical properties of the FE mesh were defined as nonlinear by using a bilinear engineering stress-strain curve.

\begin{tabular}{|l|c|l|}
\hline $\mathbf{E}[\mathbf{G P a}]$ & 207 & Young's modulus \\
\hline $\mathbf{R}_{\mathbf{p} 0.2}[\mathbf{M P a}]$ & 1350 & Yield strength \\
\hline $\mathbf{R}_{\mathbf{m}}[\mathbf{M P a}]$ & 1520 & Tensile strength \\
\hline $\mathbf{v}[-]$ & 0.3 & Poisson's ratio \\
\hline $\mathbf{\rho}\left[\mathbf{k g} / \mathbf{m}^{-3}\right]$ & 7850 & Density \\
\hline $\mathbf{A}[\mathbf{\%}]$ & 6 & Elongation \\
\hline
\end{tabular}

Table 1. Mechanical and physical properties of spring steel 1.7106 (56SiCr7 - EN 10089)

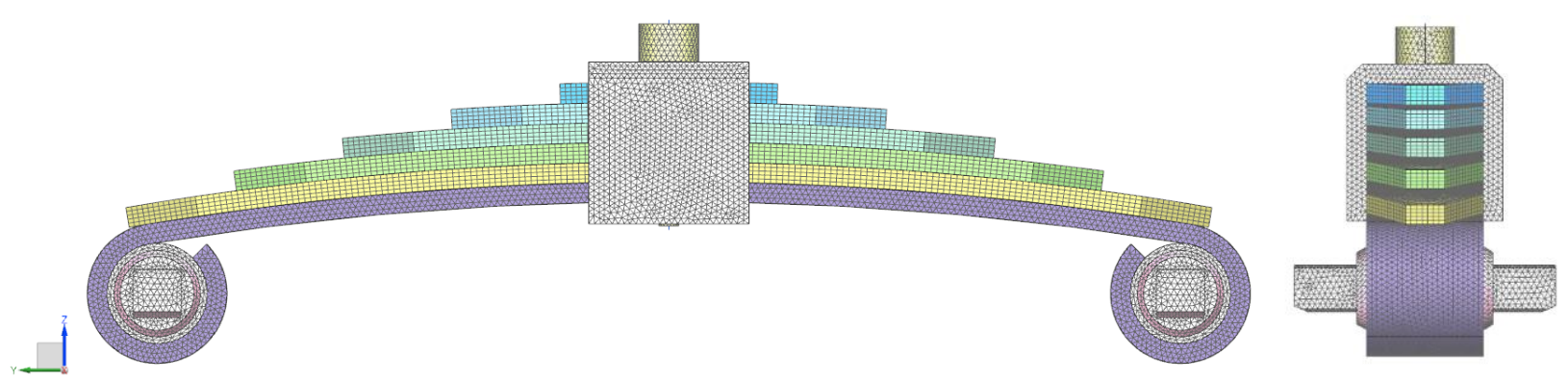

Fig. 2. Finite element model of a steel leaf spring 
The numerical simulation was solved as nonlinear by using the NX Nastran 11 solver in Siemens NX 11 software. The nonlinear solver was used because there was a large displacement in the assembly. Boundary conditions of the type 'surface to surface contact' were used between individual parts of the assembly of the leaf spring. The relevant degrees of freedom were removed in the fastening eyes and on the central pivot. Three loading conditions were solved; load from an empty vehicle; load from a fully loaded vehicle; and a dynamically increasing load from a fully loaded vehicle. The results of the individual loads are given in Fig. 3.

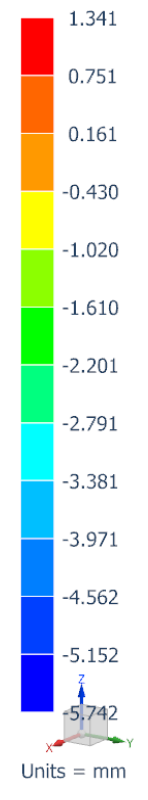

(a) load from empty vehicle

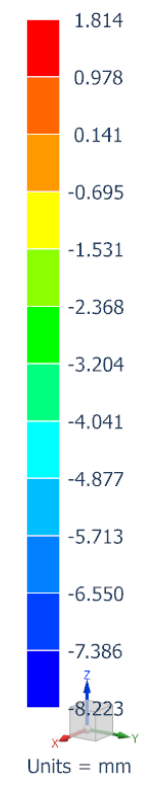

(b) load from fully loaded vehicle

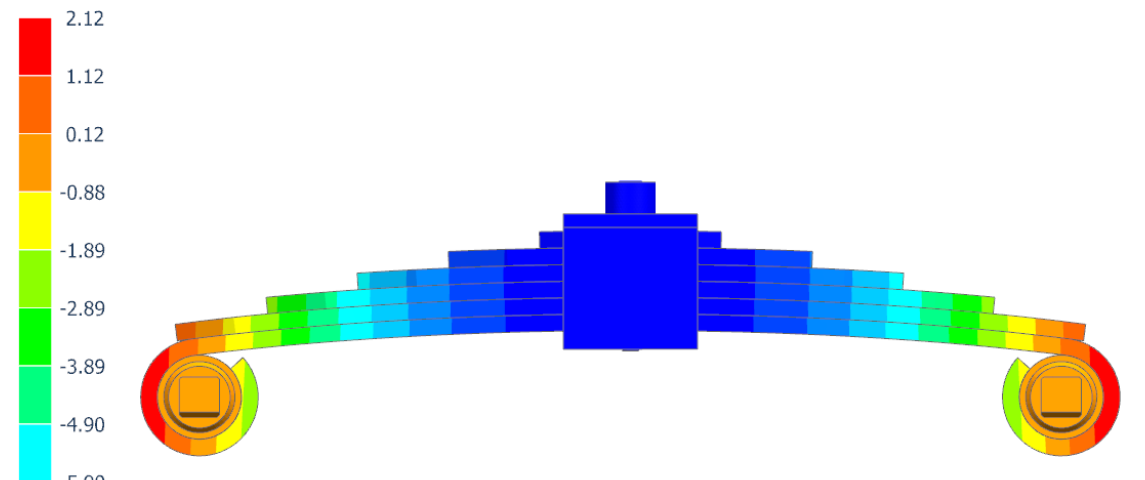

(c) load from fully loaded vehicle with dynamic increase

Fig. 3. Displacement in vertical axis (direction ' $z$ ') for different load conditions on the steel leaf spring (mm)

\subsection{Experimental measurement of the stiffness of the existing steel leaf springs}

Experimental testing of the stiffness of an existing steel leaf spring was carried out to verify the numerical simulation. The measurement was done on an Inova FU-O-250 hydraulic testing machine. The spring was attached by using a special jig that allows free motion of the spring in its longitudinal axis (direction ' $y$ '). The testing machine with the jig and the spring attached are shown in Fig. 4.

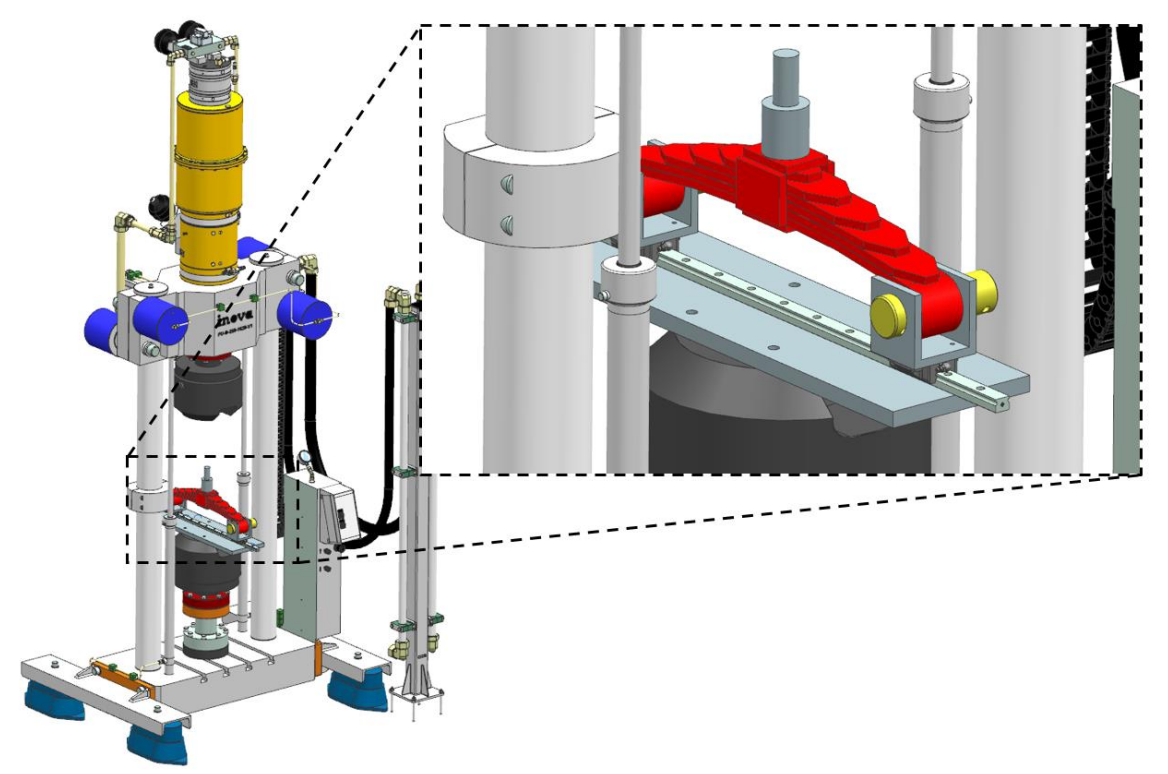

Fig. 4. Attachment of the leaf spring in the Inova F250 testing machine 
The stiffness of the first spring is given for individual load states (the load from the empty vehicle $\mathrm{F}_{\mathrm{I}}=10.6(\mathrm{kN})$; the load from the fully loaded vehicle $F_{I I}=16.1(\mathrm{kN})$; and the load from the fully loaded vehicle with dynamic increase $F_{I I I}$ $=19.7(\mathrm{kN}))$ in Fig. 5. However, these values indicate the displacement of the spring, including the deflection of the jig in which it is mounted. This 'parasitic' displacement was measured using a horizontal dial test indicator and this was subsequently deducted for the individual states [8]. The final results of the individual load conditions are given in Table 2 .

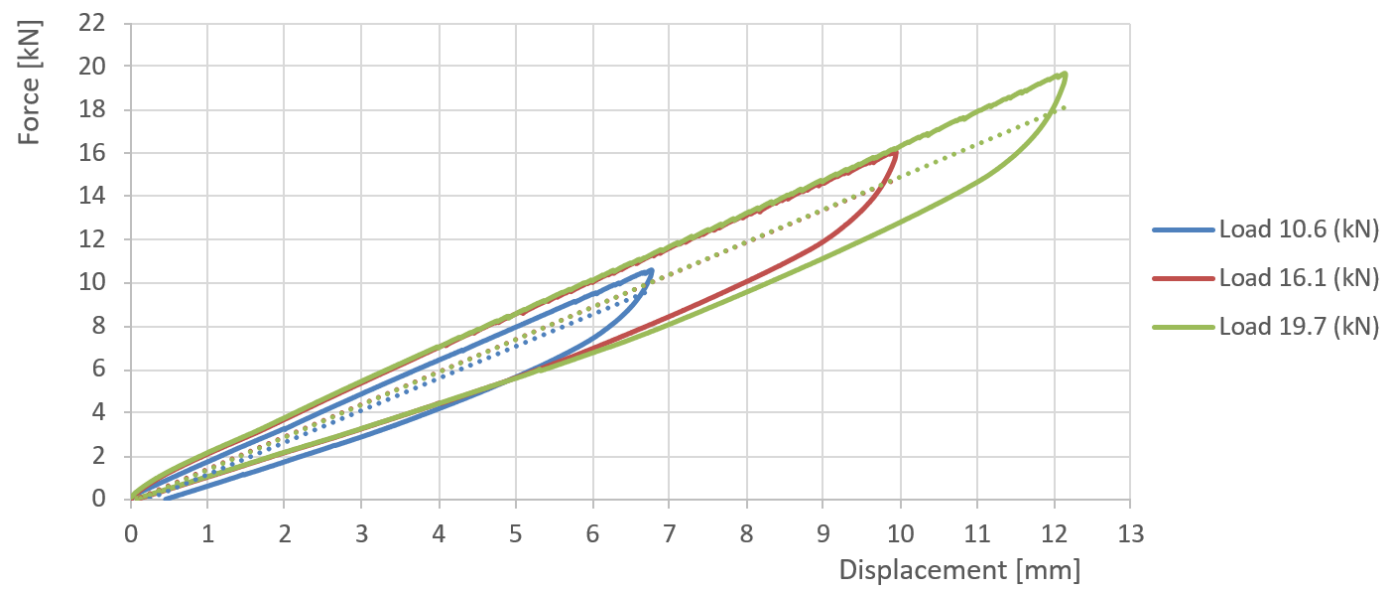

Fig. 5. The results of the experimental tests; stiffness of the steel leaf spring

\subsection{Comparison of the numerical simulations and experimental measurements of the steel leaf spring}

The data from the numerical simulation and experimental tests were compared. The final results are given in Table 2 . The maximum difference between the results is $18 \%$ (in the third load condition 'fully loaded vehicle with dynamic increase'). This value is more than satisfactory, because the numerical simulations did not take into account several influencing parameters, such as a slightly simplified geometry of the model, the values of the coefficients of friction between the contact faces of the leaves of the spring, clearance between the leaves and attachments of the spring, and many other things.

\begin{tabular}{|l|c|c|c|c|c|c|}
\hline \multirow{2}{*}{ The loading condition (kN) } & \multirow{2}{*}{$\begin{array}{c}\text { Numerical } \\
\text { simulation } \\
(\mathbf{m m})\end{array}$} & $\begin{array}{c}\text { Experimental test (mm) } \\
\text { Displacement of } \\
\text { the leaf spring } \\
\text { and preparation }\end{array}$ & $\begin{array}{c}\text { Parasitic } \\
\text { displacement of } \\
\text { the preparation }\end{array}$ & $\begin{array}{c}\text { Displacement } \\
\text { of the leaf } \\
\text { spring }\end{array}$ & $\begin{array}{c}\text { Difference } \\
(\%)\end{array}$ \\
\hline empty vehicle & $\mathbf{F}_{\mathbf{I}}=\mathbf{1 0 . 6}$ & 5.742 & 6.76 & 0.218 & 6.542 & 15 \\
\hline fully loaded vehicle & $\mathbf{F}_{\mathrm{II}}=\mathbf{1 6 . 1}$ & 8.223 & 9.94 & 0.342 & 9.598 & 17 \\
\hline $\begin{array}{l}\text { fully loaded vehicle with } \\
\text { dynamic increase }\end{array}$ & $\mathbf{F}_{\text {III }}=\mathbf{1 9 . 7}$ & 9.91 & 12.14 & 0.419 & 11.721 & 18 \\
\hline
\end{tabular}

Table 2. Results of the comparison of the numerical simulations and experimental measurements of the steel leaf spring

\section{Design of the composite leaf spring}

Several designs of the composite leaf spring were created. The choice was between either an integral or a mounted spring design. The 'mounted spring design' of the leaf spring means here the attachment of the spring to the chassis of the tram. This attachment can be created by using integrated or shaped joints. These joints in composite leaf springs are the keystone. This issue has already been dealt with in other works [9], see Fig. 6.

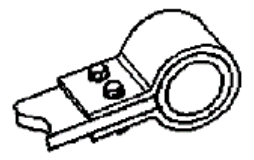

(a)

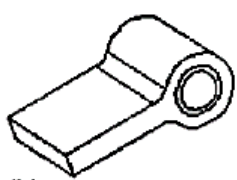

(b)

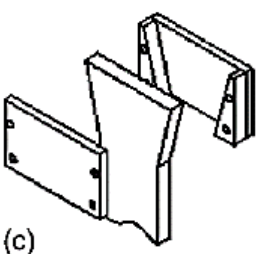

(c)

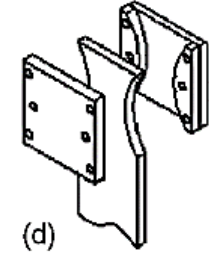

(d)

Fig. 6. Different types of joints for attaching the composite leaf spring to the vehicle body; (a) consists of a steel eye that can be bolted or pinned to the spring; (b) the eye and spring are manufactured simultaneously from the same material; (c) the spring end has a conical or (d) concave width profile [10] 
The integral design of the leaf spring was chosen as the best one. The attachment part of the spring in the shape of the unclosed eye was selected, because a closed eye creates many problems during design and manufacturing, increasing the production costs. The unclosed eyes of the spring were chosen because the leaf spring is attached using pins with a relatively large diameter, thereby leading to better distribution of the load. Disadvantages of this solution are that it is necessary to increase the stiffness of the eyes of the spring, there are lower damping properties of the spring, and there is higher pressure/stress on the contact surfaces of the spring and pin.

\subsection{Selection of the material for the composite leaf spring}

A unidirectional E-Glass fibre in combination with high toughness epoxy resin was chosen, after considering the cost/weight/mechanical properties and availability of the material. This type of material in the form of prepreg was chosen due to the large number of plies in the laminate and the relative complexity of the shape. The physical parameters of the material are given in Table 3.

\begin{tabular}{|l|c|l|}
\hline $\mathbf{V}_{\mathbf{f}}(\boldsymbol{\%})$ & 58 & Fibre Volume Fraction \\
\hline $\mathbf{V}_{\mathbf{m}}(\mathbf{\%})$ & 42 & Matrix Volume Fraction \\
\hline $\mathbf{t}(\mathbf{m m})$ & 0.78 & Thickness of the ply \\
\hline $\boldsymbol{\rho}\left(\mathbf{k g} / \mathbf{m}^{\mathbf{3}}\right)$ & 1870 & Density \\
\hline $\mathbf{E 1}(\mathbf{G P a})$ & 43 & Young's Modulus $0^{\circ}$ \\
\hline $\mathbf{E 2}(\mathbf{G P a})$ & 7 & Young's Modulus $90^{\circ}$ \\
\hline $\mathbf{G 1 2}(\mathbf{G P a})$ & 4.1 & In-plane Shear Modulus \\
\hline $\mathbf{v 1 2}(-)$ & 0.28 & Poisson's Ratio in plane 12 \\
\hline
\end{tabular}

Table 3. The physical properties of UD E-Glass prepreg $800 \mathrm{gsm}$

\subsection{Finding the geometrical parameters of the composite leaf spring}

A geometrical optimization was created to find the main shape (the main geometric parameters) of the spring. A minimization of the volume/weight of the composite body of the spring was chosen as the objective function of the geometric optimization. Individual displacement of the leaf spring in the vertical axis (from numerical simulation of the steel leaf spring) was chosen as the constrain of the geometry optimization. Next, the limits of the geometric parameters of the spring were specified. The range of these values was limited by the mounting space and individual points of the attachment to ensure compatibility with the currently used steel leaf spring. The geometric parameters of the spring are given in Fig. 7.

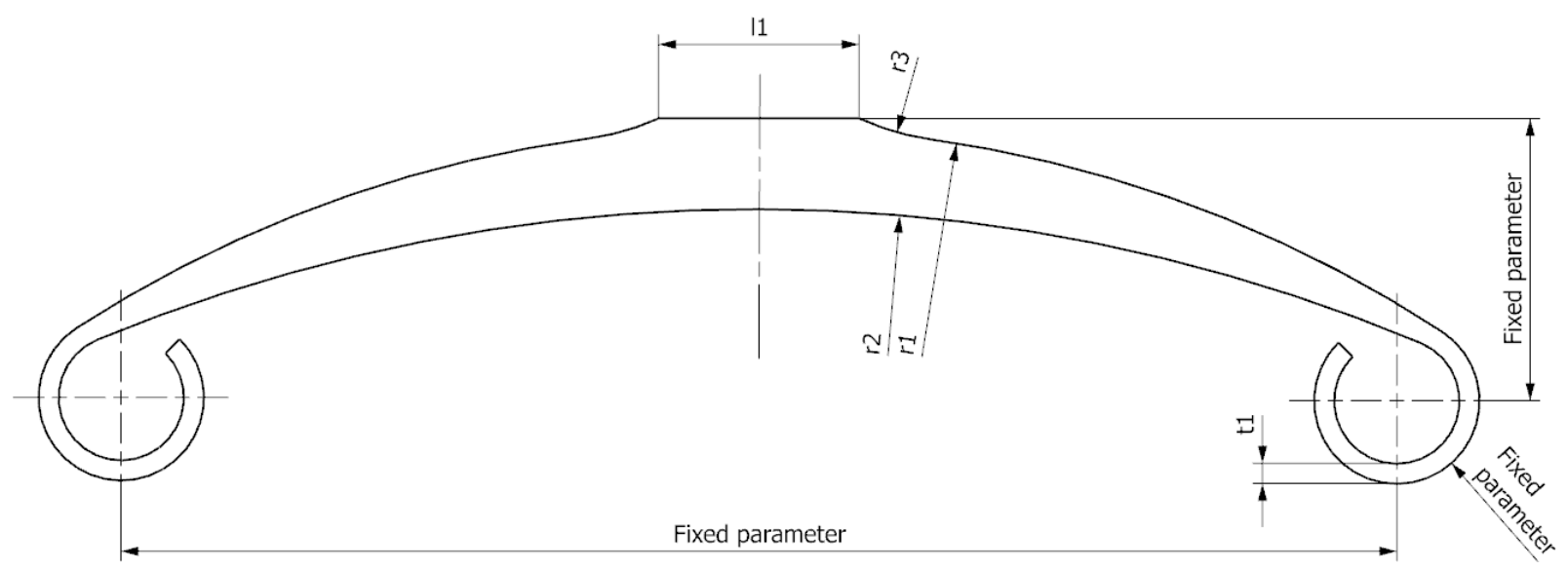

Figure 7. The geometric parameters of the geometric optimization of the composite leaf spring

\subsection{Determination of the strength of the composite leaf spring}

An advanced numerical model of the composite leaf spring was created to determine the strength of the spring. A $2 \mathrm{D}$ FE model of the spring was created from CQUAD4 elements. Then, the required number of the plies of the laminate and their physical, mechanical and geometrical parameters were defined in different zones of the 2D model. This model was transformed into a 3D FE model by using the special function 'extrude laminate' in the laminate module. This 3D FE model allows consideration of the third main direction, resin drops and interlaminar properties of the laminate; see Fig. 8. 


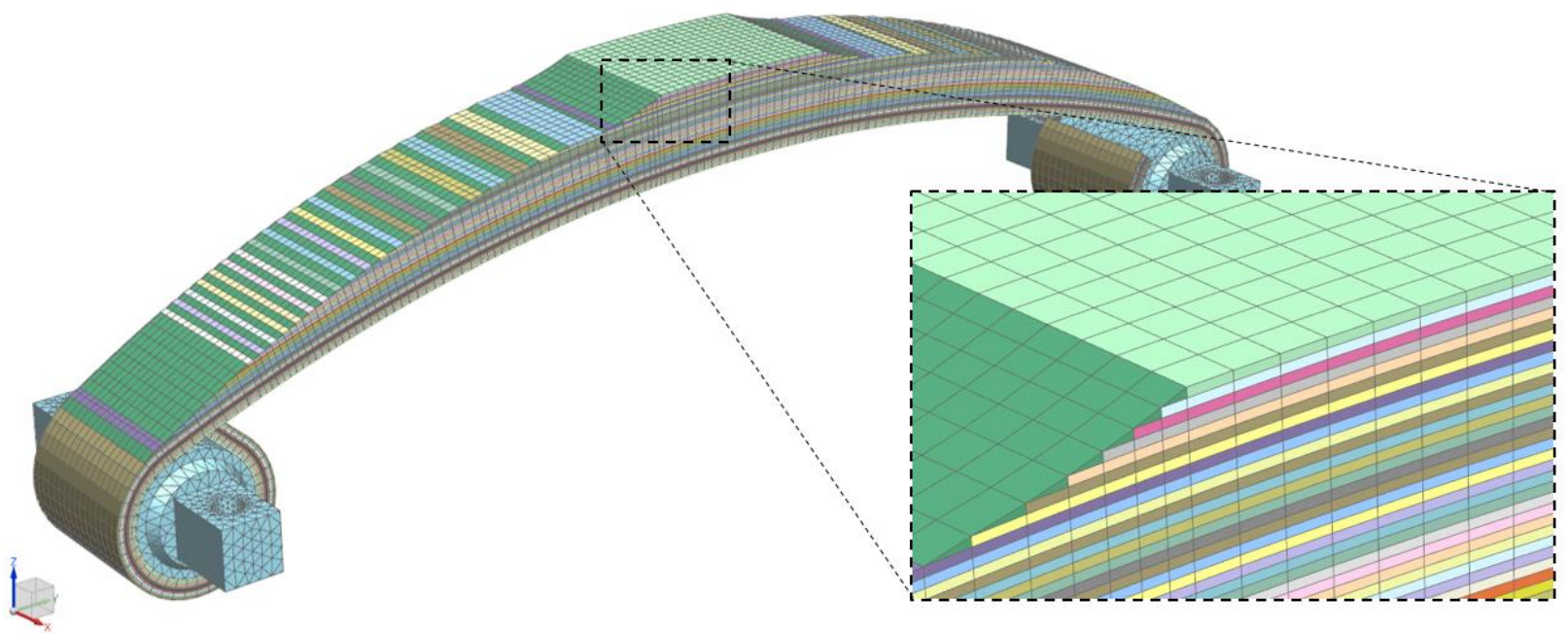

Fig. 8. FE model of the composite leaf spring

The structural analysis was carried out using non-linear solver 601 in the NX Nastran 11 solver. The maximum stress failure criterion was used to evaluate the strength of the spring. According to this theory, failure occurs when any stress component reaches the ultimate strength of the material [11].

\begin{tabular}{|c|c|c|}
\hline Failure indexes & \multicolumn{3}{|c|}{ Maximum stress criterion } \\
\hline$F_{11}$ & $\sigma_{1} / \mathrm{X}^{\mathrm{T}}$ if $\sigma_{1}>0 ; \sigma_{1} / \mathrm{X}^{\mathrm{C}}$ if $\sigma_{1}<0$ \\
\hline $\mathrm{F}_{22}$ & $\sigma_{2} / \mathrm{Y}^{\mathrm{T}}$ if $\sigma_{2}>0 ; \sigma_{2} / \mathrm{Y}^{\mathrm{C}}$ if $\sigma_{2}<0$ \\
\hline $\mathrm{F}_{33}$ & $\sigma_{3} / \mathrm{Z}^{\mathrm{T}}$ if $\sigma_{3}>0 ; \sigma_{3} / \mathrm{Z}^{\mathrm{C}}$ if $\sigma_{3}<0$ \\
\hline $\mathrm{F}_{12}$ & \multicolumn{3}{|c|}{$\left|\tau_{12} / \mathrm{S}_{12}\right|$} \\
\hline $\mathrm{F}_{23}$ & \multicolumn{3}{|c|}{$\left|\tau_{23} / \mathrm{S}_{23}\right|$} \\
\hline $\mathrm{F}_{13}$ & $\left|\tau_{13} / \mathrm{S}_{13}\right|$ \\
\hline
\end{tabular}

Table 4. Failure indexes of Maximum stress criterion (for 3D laminates)

Transverse shear failure criterion for 3D laminates (from orthotropic material) was used as the interlaminar failure criterion; see Table 5.

\begin{tabular}{|c|c|}
\hline Failure index & Transverse shear failure criterion (3D laminates) \\
\hline $\mathrm{F}_{\mathrm{IL}}$ & $\sqrt{\left(\frac{\tau_{13}}{S_{13}}\right)^{2}+\left(\frac{\tau_{23}}{S_{23}}\right)^{2}}$ \\
\hline
\end{tabular}

Table 5. Interlaminar failure criterion transverse shear (for 3D laminates)

Where $\sigma 1(\sigma 2, \sigma 3)$ is normal stress in the longitudinal (transverse) direction; XT (YT, ZT) is the longitudinal (transverse) tensile strength in the direction; $\mathrm{XC}(\mathrm{YC}, \mathrm{ZC})$ is compressive strength in the longitudinal (transverse) direction; $\tau 12$ ( $\tau 23$, $\tau 13)$ are shear stresses in plane 12 (23 or 13), and S12 (S23, S13) is shear strength in plane 12 (23 or 13) [12]. The strength properties of UD E-Glass prepreg are given in Table 6.

\begin{tabular}{|l|c|l|}
\hline $\mathbf{X}^{\mathbf{T}}(\mathbf{M P a})$ & 900 & Tensile strength $\left(0^{\circ}\right)$ \\
\hline $\mathbf{Y}^{\mathbf{T}}(\mathbf{M P a})$ & 30 & Tensile strength $\left(90^{\circ}\right)$ \\
\hline $\mathbf{Z}^{\mathbf{T}}(\mathbf{M P a})$ & 30 & Tensile strength $\left(N 90^{\circ}\right)$ \\
\hline $\mathbf{X}^{\mathbf{C}}(\mathbf{M P a})$ & 800 & Compression strength $\left(0^{\circ}\right)$ \\
\hline $\mathbf{Y}^{\mathbf{C}}(\mathbf{M P a})$ & 150 & Compression strength $\left(90^{\circ}\right)$ \\
\hline $\mathbf{Z}^{\mathbf{C}}(\mathbf{M P a})$ & 150 & Compression strength $\left(N 90^{\circ}\right)$ \\
\hline $\mathbf{S}_{12}(\mathbf{M P a})$ & 55 & In-Plane Shear Strength \\
\hline $\mathbf{S}_{\mathbf{L} \text { SS }}(\mathbf{M P a})$ & 60 & In-Lam. Shear Strength \\
\hline
\end{tabular}

Table 6. Strength properties in stress of unidirectional E-Glass prepreg 


\subsection{Results of the numerical simulation of the composite leaf spring}

The difference in the results for the displacement of the final design of the composite leaf spring and the steel leaf spring is a maximum of 5\% (1\% for the first and second load conditions, and 5\% for the third load condition). The results of the displacement of the composite leaf spring are given in Fig. 9.

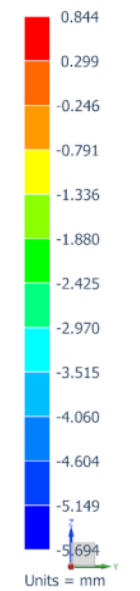

(a) load from the empty vehicle

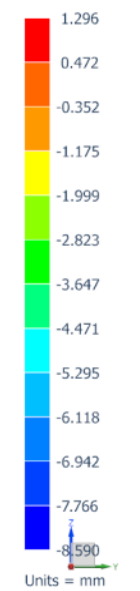

(b) load from the fully loaded vehicle

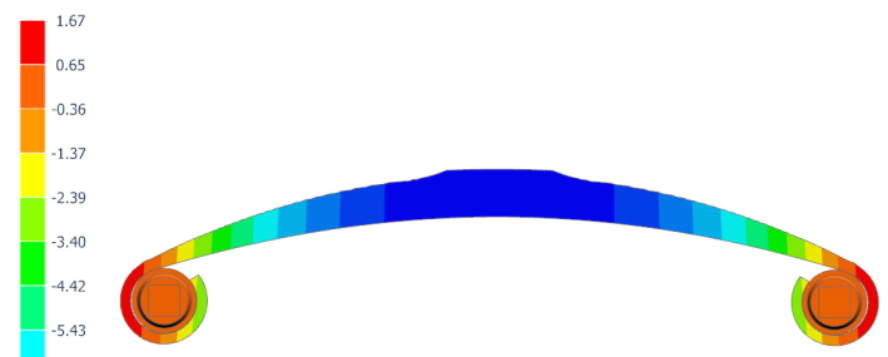

(c) load from the fully loaded vehicle with dynamic increase

Fig. 9. Displacement of the composite leaf spring in the vertical axis (' $z$ ') for different load conditions (mm)

The maximum normal stress in the leaf spring occurs in the first ply of the laminate in directions 11 and 22 . The results of the normal stress are shown in Fig. 10. for the whole model and the first ply of the composite leaf spring.
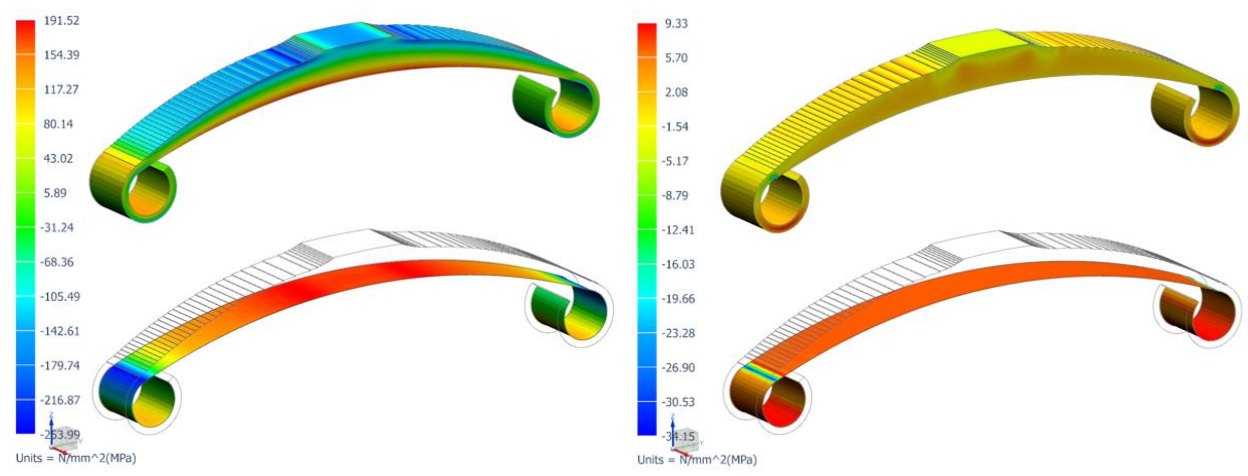

Fig. 10. Maximum normal stress in the composite leaf spring; (a) in direction 11 - whole model and first ply; (b) in direction 33 - whole model and first ply (MPa)

The maximum shear stress in the leaf spring in direction 12 occurs in the first ply of the laminate and occurs in direction 31 in ply 41. The results of the shear stress are shown in Fig. 11.
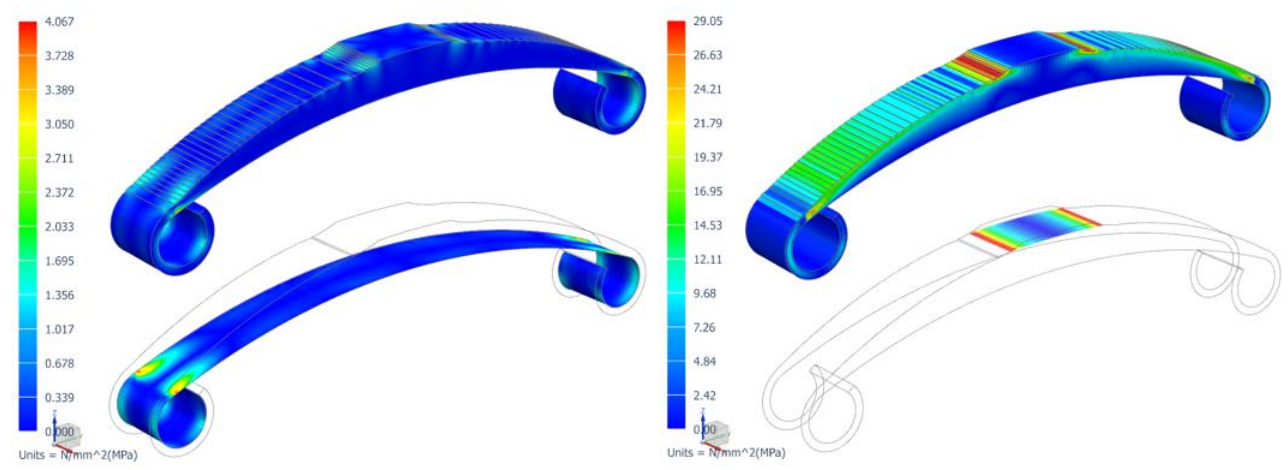

Fig. 11. Maximum shear stress in the composite leaf spring; (a) in direction 12 - whole model and first ply; (b) in direction 31 - whole model and ply 41 (MPa, Absolute value) 
Results of the normal and shear stresses were checked by using the 'maximum stress' failure criterion and the 'transverse shear' interlaminar criterion; see Fig. 12. The critical area of the failure index is on the edges of plies number 39-45, especially in shear in direction 31. In terms of the interlaminar failure index, the critical area is above the attachment pin in plies number 1-7.
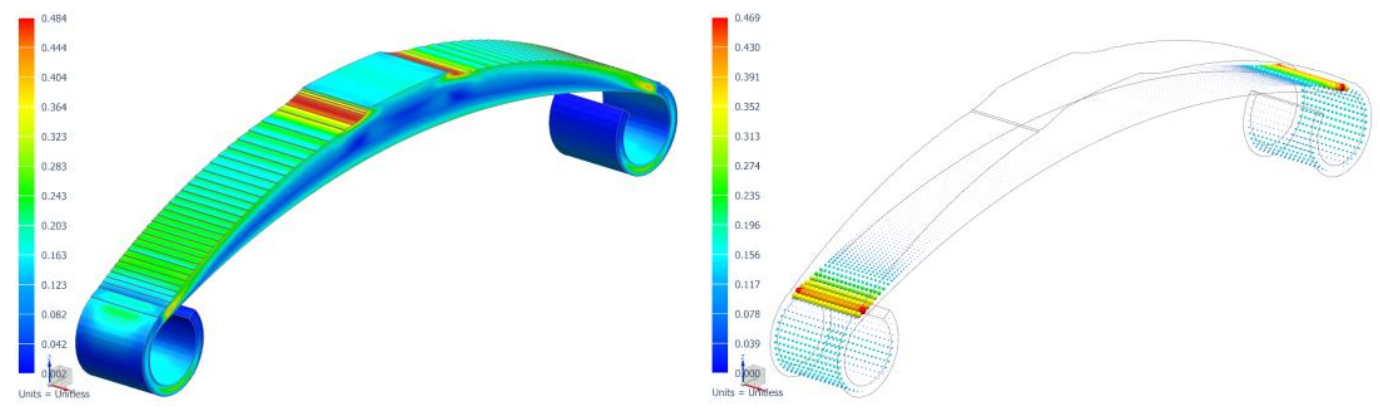

Fig. 12. Failure index of the third load condition of the leaf spring; (a) 'maximum stress' failure criterion; (b) 'transverse shear' interlaminar failure criterion- ply number 6

\section{Conclusion}

This paper deals with the optimization of a conventional steel leaf spring for a tram vehicle by using composite materials. Numerical simulations and experimental tests were carried out to obtain the main parameters. E-Glass fibre in combination with a high toughness epoxy matrix was chosen as the material. A geometric optimization based on these parameters was created to find the appropriate basic shape for the composite leaf spring. An advanced FE model which modelled the individual layers of the lamina was created. The failure indexes were evaluated by using three dimensional 'maximum stress' failure criterions and the 'transverse shear' interlaminar failure criterion. The weight of the leaf spring was reduced by using this design from $12.6(\mathrm{~kg})$ to only $1.9(\mathrm{~kg})$, meaning a weight reduction of more than $80 \%$.

We are currently working on manufacturing several composite leaf springs for experimental testing and verification of the numerical simulations.

\section{Acknowledgments}

This work has been prepared under the project LO1502 'Development of the Regional Technological Institute' under the auspices of the National Sustainability Programme I of the Ministry of Education of the Czech Republic aimed at supporting research, experimental development and innovation.

\section{References}

[1] Mallick, P. K. Composites Engineering Handbook. New York: M. Dekker, 1997. Print.

[2] Morris, C.J. Composite integrated rear suspension, Composite Structures, Volume 5, Issue 3, 1986, Pages 233-242, ISSN 0263-8223.

[3] Beardmore, P.; Johnson, C.F. The potential for composites in structural automotive applications, Composites Science and Technology, Volume 26, Issue 4, 1986, Pages 251-281, ISSN 0266-3538.

[4] Daugherty, R. L. Composite Leaf Springs in Heavy Truck Applications. K. Kawata, T.Akasaka (Eds). Composite Materials Proceedings of Japan-US Conference Tokyo, 1981.

[5] Krall, S.; Zemann, R. Investigation of the Dynamic Behaviour of CFRP Leaf Springs, Procedia Engineering, Volume 100, 2015, Pages 646-655, ISSN 1877-7058

[6] Mahdi, E.; Alkoles, O.M.S.; Hamouda, A.M.S.; Sahari, B.B.; Yonus, R.; Goudah, G. Light composite elliptic springs for vehicle suspension, Composite Structures, Volume 75, September 2006, Pages 24-28, ISSN 02638223.

[7] Talib A.R.A., Aidy A., Goudah G., Nur Azida Che Lah, Golestaneh A.F., Developing a composite based elliptic spring for automotive applications, Materials \& Design, Volume 31, Issue 1, January 2010, Pages 475-484, ISSN 0261-3069.

[8] Wahl, A. M. Mechanical Springs. New York: McGraw-Hill, 1963. Print.

[9] J.P. Hou, J.Y. Cherruault, I. Nairne, G. Jeronimidis, R.M. Mayer, Evolution of the eye-end design of a composite leaf spring for heavy axle loads, Composite Structures, Volume 78, May 2007, Pages 351-358, ISSN 0263-8223.

[10] Mahmood M Shokrieh, Davood Rezaei, Analysis and optimization of a composite leaf spring, Composite Structures, Volume 60, Issue 3, May-June 2003, Pages 317-325, ISSN 0263-8223.

[11] Vasiliev Valery V., Morozov Evgeny V.: Advanced Mechanics of Composite Materials and Structural elements, 3rd Edition. ISBN: 978-0-08-098231-1, Elsevier, Oxford, 2013.

[12] Sedláček, F., Lašová, V., Kottner, R., Bernardin, P. Comparison of Numerical Simulation and Experiment of a Flexible Composite Connecting Rod. In Industrial Engineering. 2015. s. 1-6. ISBN: 978-9949-23-804-0, ISSN: 2346-6138 